\title{
THE DIVERSITY OF OBJECTIONS TO INEQUALITY
}

by

\section{T. M. SCANLON}

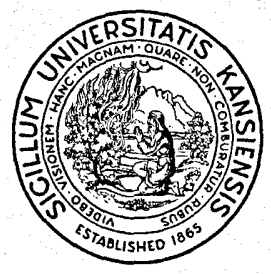

The Lindley Lecture

The University of Kansas

1996 
The E. H. Lindley Memorial Lectureship Fund was established in 1941 in memory of Ernest H. Lindley, Chancellor of the University of Kansas from 1920 to 1939 . In February $1941 \mathrm{Mr}$. Roy Roberts, the chairman of the committee in charge, suggested in the Graduate Magazine that

the Chancellor should invite to the University for a lecture or a series of lectures, some outstanding national or world figure to speak on "Values of Living"-just as the late Chancellor proposed to do in his courses "The Human Situation" and "Plan for Living."

In the following June Mr. Roberts circulated a letter on behalf of the Committee, proposing in somewhat broader terms that

The income from this fund should be spent in a quest of social betterment by bringing to the University each year outstanding world leaders for a lecture or series of lectures, yet with a design so broad in its outline that in the years to come, if it is deemed wise, this living memorial could take some more desirable form.

The fund was allowed to accumulate until 1954, when Professor Richard McKeon lectured on "Human Rights and International Relations." The next lecture was given in 1959 by Professor Everett C. Hughes, and has been published by the University of Kansas School of Law as part of his book Students' Culture and Perspectives: Lectures on Medical and General Education. The selection of lecturers for the Lindley series has since been delegated to the Department of Philosophy.

$$
\text { * * * }
$$

A Volume of Lindley Leotures

Dellvered at the University of Kaneas

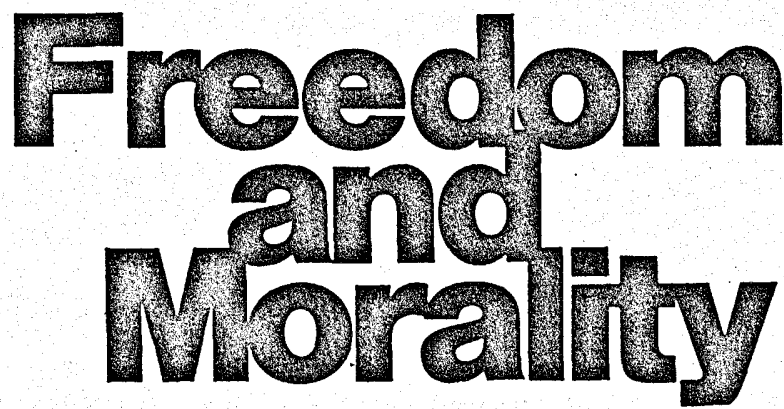

Alchard B. Brandt

Moral Philosophy and the Analysis of Language

Rodorlek M. Chisholm Human Freedom and the Selt

Stuart Hampohire Freedom of Mind

WHIIam K. Frankene Some Betiets about Justice

Wilfrid sollars

Form and Content in Ethical Theoty
J. N. FIndlay

The Systematic Unity of Value

Alan Gowirth Moral Rationatity

Albert Hofatadter Rellections on Evil

Paut Rlcoour What is Dialectical?

\section{R. M. Hare}

Some Confusions about

Subjectivity

Edited with an Introduction by John Bricke
The volume can be purchased for $\$ 6.00$ from the Library Sales Office, University of Kansas Libraries, Lawrence, Kansas (U.S.A.) 66045. Please include a $50^{\circ}$ handling fee, $75^{\circ}$ outside the United States. 


\title{
THE DIVERSITY OF OBJECTIONS TO INEQUALITY
}

\author{
by \\ T. M. SCANLON
}

Alford Professor of Natural Religion, Moral Philosophy, and Civil Polity

Harvard University

The Lindley Lecture, University of Kansas

February 22, 1996 
C Copyright 1997 by Department of Philosophy University of Kansas 


\title{
The Diversity of Objections to Inequality
}

\author{
T. M. Scanlon
}

I believe that equality is an important political goal. That is to say, virtually every society is marked by forms of inequality the elimination of which is a political objective of the first importance. But when I ask myself why I think it so important that these inequalities should be eliminated, I find that my reasons for favoring equality are in fact quite diverse, and that most of them can be traced back to fundamental values other than equality itself. The idea that equality is, in itself, a fundamental moral value turns out to play a surprisingly limited role in my reasons for thinking that many of the forms of inequality which we see around us should be eliminated.

When I say that the idea of equality plays surprisingly little role in my thinking here, I have in mind an idea of substantive equality-that it is morally important that people's lives or fates should be equal in some substantive way: equal in income, for example, or in overall welfare. This is in contrast to a merely formal notion of equal consideration, as stated for example in the principle that the comparable claims of each person deserve equal respect and should be given equal weight. This is an important principle. Its general acceptance represents an important moral advance, and it provides a fruitfuleven essential-starting point for moral argument. But taken by itself it is too abstract to exercise much force in the direction of substantive equality. As Thomas Nagel and Amartya Sen have both pointed out, ${ }^{1}$ even a rights theorist such as Robert Nozick, who would not normally be counted an egalitarian, could accept this principle, since he holds that everyone's rights deserve equal respect. My hypothesis is that the bare idea of equal consideration leads us to substantively egalitarian consequences only via other more specific values that I will enumerate, most of which are not essentially egalitarian.

In saying this I do not mean to attack equality or to "unmask" it as a false ideal. My aims, rather, are clarification and defense: clarification, because I believe that we can understand familiar arguments for equality better by seeing the diversity of the considerations on which they are based; defense, because I think that the case for pursuing particular forms of equality is strengthened when we see how many different considerations point in this direction. Opponents of equality seem most convincing when they can portray equality as a peculiarly 
abstract goal-conformity to a certain pattern-to which special moral value is attached. ${ }^{2}$

I will begin by distinguishing what seem to me to be the fundamental moral reasons lying behind our objections to various forms of inequality. I will then illustrate these ideas by showing how they figure in various ways in Rawls's views about distributive justice. Finally, I will return to examine one of these values-the one which seems the most purely egalitarian-in more detail. Let me turn, then, to an enumeration of our reasons for finding the pursuit of equality a compelling political goal.

In some cases our reason for favoring the elimination of inequalities is at base a humanitarian concern-a concern, for example, to alleviate suffering. If some people are living under terrible conditions, while others are very well off indeed, then a transfer of resources from the better to the worse off, if it can be accomplished without other bad effects, is desirable as a way of alleviating suffering without creating new hardships of comparable severity.

The impulse at work here is not essentially egalitarian. No intrinsic importance is attached to narrowing or eliminating the gap between rich and poor; this gap is important only because it provides an opportunity-a way of reducing the suffering of some without causing others to suffer a similar fate, and the strength of this reason for moving toward greater equality is a function of the urgency of the claims of those who are worse off, not of the magnitude of the gap which separates them from their more fortunate neighbors. ${ }^{3}$

In characterizing this first reason, I have spoken of "the alleviation of suffering" in order to present this reason in its strongest form, but its force may still be felt in cases where, although the term "suffering" would be inappropriate, those who are "worse off" are still living under conditions which we regard as seriously deficient. This force fades away, however, as we imagine the situation of both rich and "poor" to be greatly improved, while the difference between them is held constant (or even increased). We may still feel, even in this improved state, that the difference between richer and poorer ought to be reduced or eliminated. Our reason for thinking this will not, however, be the humanitarian concern I am presently concerned with, but some different reason, perhaps a more truly egalitarian one. 
One possible reason for objecting to these differences would be the belief that it is an evil for people to be treated as inferior, or made to feel inferior. Social practices conferring privileges of rank or requiring expressions of deference are objectionable on this ground, for example. So also is the existence of prevailing attitudes of superiority (e.g. racial superiority) even when these are not expressed in or taken to justify economic advantage or special social privileges. Large differences in material well-being can be objectionable on the same ground: when the mode of life enjoyed by some people sets the norm for a society, those who are much worse off will feel inferiority and shame at the way they must live.

The egalitarian character of this objection is shown by the fact that it provides a reason specifically for the elimination of the differences in question rather than for the improvement of the lot of the worse off in some more general sense. This is obviously so where the differences are purely ones of status. But even where the basis of inferiority is a difference in material well-being, the aim of avoiding stigmatization can in principle provide a reason for eliminating the benefits of the better off (or for wishing that they had never been created) even if these cannot be transferred to the worse off. If simply eliminating these benefits seems wrong (perhaps even perverse), this judgment reflects a willingness to sacrifice the aim of equality (in the sense under consideration) for the sake of material benefit. This aim - the ideal of a society in which people all regard one another as equals- has played an important role in radical egalitarian thinkinga more important role than the idea of distributive justice which dominates much discussion of equality in our own time. This ideal may seem utopian, and there are interesting difficulties about how it should be understood. I will return to these matters later in my lecture, after some other reasons for favoring equality have been considered.

A third reason for the elimination of inequalities is that they give some people an unacceptable degree of control over the lives of others. The most obvious example is economic power. Those who have vastly greater resources than anyone else not only enjoy greater leisure and higher levels of consumption but also can often determine what gets produced, what kinds of employment are offered, what the environment of a town or state is like, and what kind of life one can live there. In addition, economic advantage can be translated into great political power-for example into the kind of power that the recent Campaign Financing Laws were intended to curb. 
This example brings me to a fourth reason for pursuing equality, which overlaps with the one just mentioned but should be listed separately. Some forms of equality are essential preconditions for the fairness of certain processes, and the aim of making or keeping those processes fair may therefore give us a reason to oppose inequalities of these kinds, at least when they are very large. So, for example, in the case just mentioned, instead of speaking of unacceptable degrees of political power (thus appealing to the value of political liberty) we might have spoken instead of preserving the fairness of the political process. These two forms of argument overlap in this particular case, but they are in fact distinct. When inequality of starting points undermines the fairness of a process, domination of those who are placed at a disadvantage does not always result, since the process may confer no power but only honor or the opportunity for a more pleasant and rewarding life. Unfairness, however, remains, and can take several forms: some people, can simply be excluded from competition, or background conditions such as inequalities in training and resources can render the competition unfair. So the idea of equality of opportunity-as expressed in the familiar metaphors of a "fair race" or "a level playing field"-provides a familiar example of this fourth reason for objecting to inequality: inequalities are objectionable when they undermine the fairness of important institutions.

As the common contrast between "equality of opportunity" and "equality of results" indicates, this idea is only weakly egalitarian, since it can be compatible with large inequalities provided that they result from a fair process and do not disrupt the fairness of on-going competition. But, as I will now argue, the idea of a fair procedure can also provide another kind of reason for insisting on equality of outcomes. (This is my fifth reason for objecting to inequalities.)

Suppose that the members of a group have equal claims to a certain form of benefit, such as the wealth produced by their combined efforts. If a distributive procedure is supposed to be responsive to these claims, then it will be unfair if (absent some special reason) it gives some of these people a higher level of benefit than others. This provides, in schematic form, an argument which leads us to a prima facie case for equality in a certain dimension of benefit. Its starting points include an idea of fairness together with substantive premises about the claims that the people in question have to this benefit and about the function of a particular procedure. To generate a particular egalitarian conclusion we need to fill in the relevant premises, and the force of this conclusion will depend on how plausible these premises 
are. We might, for example, begin with the idea that, other things equal, all individuals have equal claims to welfare. This sounds like quite a strong claim, but it might be a fairly weak one: much depends on how many things there are that might not be equal. A natural first step in specifying this would be to make explicit the fact that one class of relevant differences are differences in the choices people have made. This yields the principle that people ought to be equal in the levels of welfare they enjoy apart from differences in welfare resulting from their own free choices. I have not included an "other things equal" clause in the statement of this principle, but I assume that it is still only one moral idea among others, which might have to be sacrificed or balanced for the sake of other values.

These values enter in when we begin to specify the other premise mentioned above, that is, to ask what range of actions might be thought of as part of a "procedure" which is supposed to be responsive to these equal claims. It would not be very plausible, for example, to claim that all of our actions have this function (or must be thought of as part of a "procedure" with this aim). It does not seem that in general we are under even a "prima facie" duty to promote the equal welfare of all. A more plausible claim would be that the state, or in Rawls's phrase "the basic institutions of society," should be understood in this way, that is, as an institution whose function it is to respond to the (equal) claims to welfare of all of its subjects (equal, that is, apart from differences arising from individual choice). This is what might be called the "parental" conception of the state. I choose that term because it seems to me that the claim of unfairness to which this conception gives rise is similar to the one raised by a child who protests the fact that a sibling has received some benefit by saying "That's not fair!". The similarity rests in the fact that both claims are grounded in an idea that the agent to whom it is addressed is under an equal duty to promote the welfare of each of the parties in question.

As this description no doubt suggests, I do not myself find this conception of the state altogether compelling. A more plausible conception, and hence a more plausible case for equality, can be obtained if we view the citizens not merely as beneficiaries but rather as participants. It might be said, for example, that the basic institutions of a society should be seen as a cooperative enterprise producing certain benefits, and that citizens, as free and equal participants in this process, have (at least prima facie) equal claim to the benefits they collectively produce. (It is worth emphasizing that this premise does not lead to the conclusion that people should be equal in all respects, 
but only in their shares of these socially produced benefits. It therefore provides a plausible basis for some form of "equality of resources.")

This claim to equal outcomes is not indisputable. It might be maintained, for example, that insofar as social institutions are seen as cooperative undertakings for mutal benefit the claims of participants to its products are not equal but proportional to their contributions. My task here is not, however, to offer a full defense of the argument I have sketched, but rather to identify it as one among several sources of egalitarianism.

To summarize, I have identified five reasons for pursuing greater equality. The elimination of inequalities may be required in order to

(1) Relieve suffering or severe deprivation

(2) Prevent stigmatizing differences in status

(3) Avoid unacceptable forms of power or domination

(4) Preserve the equality of starting places which is required by procedural fairness.

In addition,

(5) Procedural fairness sometimes supports a case for equality of outcomes.

At least two of these reasons, (1) and (3), are based on powerful moral ideas that are not fundamentally egalitarian. The ideas behind (2), on the other hand, are clearly egalitarian, but while they are certainly important they do not seem to have as much moral force as the humanitarian ideals expressed in (1). Reason (4) is only weakly egalitarian, since the idea of procedural fairness which supports it is compatible with great inequalities of some kinds as long as these do not undermine the fairness of the continuing process. This leaves (5) and (2) as the clearest expressions of egalitarianism. Reasons of type (5) are at least as powerful as those to which (2) appeals, but these reasons come in a variety of forms, which vary in strength. The idea which they have in common is not that all men and women are created equal but rather that if all the members of a certain group have prima facie equal claim to benefit in a certain way then a fair procedure for distributing such benefits must (in the absence of special justification) result in equal benefits. I imagine that everyone would agree to the truth of this conditional statement, but its uncontroversial character is purchased by packing a great deal into its antecendent. The egalitarian thrust of (5) arises from the claim that this antecedent is true in an important range of cases-e.g. that participants in many cooperative ventures do have prima facie equal claims 
to the benefits produced, and, specifically, that this is so in the case of the basic institutions of a society.

Are there further reasons for favoring equality which I have omitted? The main possibility is a straightforward moral ideal of substantive equality, that is to say, the idea that a society in which people are equally well-off (as determined by some appropriate measure) is for that reason a morally better society. This is certainly an intelligible and even an appealing idea. But how much of a role does it actually play in our moral thinking? Reasons (1) through (5) discussed above are not, I think, derived from this idea. They are much more specific and have independent moral force. Once the distinctness of these reasons is recognized, how much force does the substantive ideal just mentioned retain? My own sense is that it may have the status of one appealing social ideal among others, but that it lacks the particular moral urgency which the idea of equality seems to have in ordinary political argument, a force which derives, I believe, from the other reasons I have listed.

\section{II}

To illustrate these five reasons for pursuing equality, I want now to consider how they figure in Rawls's theory of justice and account for much of the egalitarian content of his view. It may seem at first that Rawls's Difference Principle, which calls for us to maximize the expectations of the worst off, draws on the first of the reasons I mentioned: a humanitarian concern with the fate of the worst off. The argument for the use of the maximin rule, for example, seems to appeal to a first-person version of this concern insofar as it relies on the idea that there are certain outcomes "that one could hardly accept" and that it is rational, under the circumstances of the Original Position, to be primarily concerned with avoiding these outcomes, in comparison with which other gains are relatively insignificant. ${ }^{4}$ Like the humanitarian case for equality mentioned above, this reason for the Difference Principle would diminish in force if the possible positions of the worst off were to become more and more bearable, holding constant the distance between these positions and those of the better off.

But the case for the Difference Principle is not primarily "humanitarian." That is to say, it is not primarily based in sympathy for the worst off. Rawls's central idea lies, rather, in his emphasis on seeing the basic structure of society as a fair system of cooperation, and 
on taking the question of justice to be that of how the benefits of such cooperation are to be shared. The case for the Difference Principle then rests on an appeal to reasons (4) and (5) above: the need for equality of starting points as a precondition of procedural fairness, and the appeal of equal outputs as a fair mode of distribution. Consider the latter first. This argument for the Difference Principle can be put in two steps. The first step is the prima faciecase for equal shares as a fair way to distribute the fruits of cooperation among those who have participated in producing them. The second step is the idea that departures from equality which leave everyone better off cannot reasonably be objected to, as long as (a) the positions to which greater rewards are attached are "open to all under conditions of fair equality of opportunity" and (b) these inequalities do not give rise to unacceptable stigmatization of some members of the society as inferior.

Rider (a) incorporates the fourth idea mentioned above, that (at least a degree of) equality of starting places has to be preserved as a precondition for procedural fairness. At least it does so if, as is clearly Rawls's intent, "fair equality of opportunity" is understood to include more than the mere absence of legal restrictions and discriminatory practices. ${ }^{5}$ The fact that this idea- of the importance of preserving at least approximate equality of starting positions-occurs only in a rider, as a constraint on permissible inequalities and a way of warding off possible objections, should not be allowed to obscure the central role it plays in the positive case for the Difference Principle. This centrality is shown in the fact that this idea is the basis of one of the main objections which Rawls levels against alternatives to his conception of distributive justice. ${ }^{6}$ For example, his objection to the laissez faire conception of justice that he calls "the system of natural liberty" is that the operation of this sytem over time can lead to great differences in family wealth with the result that individuals born into different positions in the society will have vastly different opportunities for education and for entry in to economic life, as well as different dispositions to make use of the opportunities they do have. An important part of the case for Rawls's Two Principles is the fact that institutions which satisfy them will not be subject to this objection, and that, more generally, these principles guarantee the kind of background necessary for a system of pure procedural justice.

Along side of this argument, and complementary to it, is the idea that the system of natural liberty should be rejected because it allows people's life prospects to be determined by factors, such as fortunate family circumstances, which are "arbitrary from a moral point of 
view." This might be understood as a restatement of the objection that I have just summarized: the system is unacceptable because it allows life prospects to be determined by competition under "arbitrary" conditions, rather than under conditions of "background fairness." But it can also be seen as an appeal to type (5) unfairness: a system of natural liberty is unfair because outcomes which are sensitive to the "accidents of birth" are not responsive to the equal claims of "free and equal cooperating members of society."

Because the distributive shares assigned to members of one generation are a large part of what determines the starting places of the next, considerations of these two kinds (equality of starting places and equality of distributive shares) tend to converge. Insofar as the focus is on fair sharing of what individuals have produced as free and equal members of a cooperative scheme, (5) seems to be particularly central; when the focus is on fairness to individuals born into certain social positions, their productive lives still lying ahead, (4) comes into play. Rawls certainly appeals at various points to reasons of both types. They are complementary but may differ in dialectical strength.

As I mentioned above, the force of the idea that fairness demands equal distributive shares depends on a prior claim that as participants in a cooperative scheme the individuals in question have equal claim to the fruits of their cooperation. This is an appealing moral idea, but a controversial one to take as the starting point for an argument in support of a particular conception of justice. By contrast, appeals to (4) rest, in the first instance, on the more broadly shared idea that the legitimacy of holdings is undermined when the process through which they are gained is unfair. The controversy in this case is over conditions of fairness: What kind of initial conditions must be provided in order for a process to be one whose outcomes cannot be complained of? There is certainly wide disagreement on this question, ${ }^{7}$ but there may also be more scope for internal argument (about how best to extrapolate from shared examples, etc.).$^{8}$

Let me return now to the idea of "stigmatization." I incorporated this idea as a rider on my restatement of Rawls's Difference Principle: economic inequalities are unjust if they give rise to unacceptable stigmatization of some as inferior. Rawls did not, of course, deal with this problem through a separate rider. Instead, his measure of what it is for the lot of the worst off to be improved includes, as one component, "the social bases of self-respect." His formulation thus allows, at least formally, for the possibility that loss in this dimension of wellbeing might be compensated for by other advantages. I do not believe 
that this difference in formulation will make much difference in practice, but I leave that question open. ${ }^{9}$ What is important for present purposes is that Rawls took it to be an important feature of his conception of justice that it provided a more secure protection for individual self-respect than did alternative conceptions such as utilitarianism or the "system of natural liberty." He stresses that this protection is provided not only by the Difference Principle but also by his First Principle, which requires that the equal status of all citizens should be secured by their having equal civil and political rights and liberties.

The equality demanded by this principle is, on its face, rather formal: it demands that all citizens have the most extensive system of equal basic liberties. This is formal insofar as it deals only with what the laws and constitution specify. But Rawls also asserts, as an important advantage of his Difference Principle, that by assuring nearly equal economic shares it guarantees what he calls the "fair value" of these rights and liberties. The idea, then, is that the Difference Principle will be sufficiently egalitarian to insure the fairness of the political process (an instance of (4)) and thus to prevent some from exercising an unacceptable degree of power over others (3).

To conclude this brief discussion of Rawls: his argument for his Two Principles of justice, in particular for the second of these principles, appeals directly or indirectly to at least four of the grounds for equality mentioned above, namely numbers (2) through (5), and perhaps to (1) as well. But (4), or a combination of (4) and (5), appears to play the most central role. This emphasis on the claims of citizens qua participants in a fair procedure helps to explain the fact that the Difference Principle is concerned with individuals' shares of "primary social goods" (i.e., the fruits of their cooperation) rather than with their levels of overall welfare.

\section{III}

The second reason that I presented, in Section I, for objecting to inequality was based on the idea that "it is an evil for people to be treated as inferior, or made to feel inferior." I want now to consider, at least in a preliminary way, some of the difficulties involved in determining more exactly how this objection is to be understood. My initial statement of this objection was cautiously ambivalent. It consisted of two parts, the first of which suggests that what is objectionable is a certain form of treatment (being treated as inferior, or not being "treated as 
an equal") and the second suggests that the evil is an experiential one (being made to feel inferior). More needs to be said both about how this "experiential" component is to be understood and about how it is supposed to be related to the underlying forms of treatment in order to give rise to the objection in question.

The experiential evil involved here can be characterized in several different ways-indeed, there are several different kinds of experience that one might have in mind. Let me distinguish two broad categories. The first, more "individualistic," characterization emphasizes what might be called damage to individuals' sense of self-worth: such things as feelings of inferiority and even shame resulting from the belief that one's life, abilities or accomplishments lack worth or are greatly inferior to those of others. ${ }^{10}$ The second category emphasizes damage to the bonds between people: what might be called the loss of fraternity resulting from great differences in people's material circumstances, accomplishments and the social importance accorded to them. Unlike the first, this is a loss suffered by the better off and worse off alike, and perhaps it is the more fully egalitarian of the two. Much more could be said by way of characterization of these two classes of experiential evils, but I will not pursue these questions here. My concern will instead be with the independence of these evils from other objections to inequality and with the particular difficulty of avoiding them. I will concentrate on evils of the first of the two kinds just distinguished, but I believe that the same points apply as well to evils of the second sort.

It is of course quite possible that someone might suffer from these forms of undesirable consciousness (such as a sense of inferiority and worthlessness) simply from psychological causes that have nothing to do with the actual facts of one's society. This would be a misfortune, but not the basis of an objection to social institutions. Such objections arise only when institutions cause people to have these undesirable feelings. Let me consider three ways that institutions might do this.

First, they might do it by depriving some people (but not others) of basic rights: denying them the right to move freely in public, the right to participate in politics, or the right to compete for other valued positions in the society. People treated in these ways would certainly not be treated "as equals." But the main objection in such a case would be to these forms of treatment themselves, not to their experiential consequences. So I will set this case aside.

Second, institutions which were not otherwise unjust might nonetheless treat some people in ways that could only be understood as in- 
tended to express the view that they were inferior. This might be done by, say, attaching special "dishonorific" titles to their names, or by requiring them to defer to members of other groups whenever they met in public. These signs of status are clearly objectionable, and our reasons for objecting to them depend on the fact that those subject to these forms of treatment could reasonably feel shamed and humiliated by them.

But the same objection would apply to institutional arrangements that, while they did not have the aim of expressing inferiority, nonetheless had the effect of giving rise to feelings of inferiority on the part of most reasonable citizens. This is my third case. The obvious examples are economic institutions which yield such great disparities of wealth and income that some people experience shame and humiliation because they must live in a way that is far below what most people in the society regard as minimally acceptable. There are also non-economic examples, such as a society in which almost everyone places great value and importance on certain forms of accomplishment, forms that many, but not all, can attain, and in which it is regarded as a great misfortune not to be "successful" in these ways. These views imply that those whose accomplishments do not measure up are inferior in important ways. In this respect this case is like my second one; but it is not the point of these practices (as it was of those in the previous case) to mark some out as inferior. That is merely the side effect of the recognition of what is seen as valuable accomplishment and good fortune. While these two cases may be different, I will not make much of this difference here, but will suppose that both the second and the third cases I have just distinguished give rise to the objection to inequality that I earlier called "stigmatizing differences in status." My focus in the remainder of this lecture will be on the question of whether and how these objections can be met or avoided.

Consider first a familiar example of objectionable inequality, the phenomena of racial and sexual discrimination in our societies. Women and African Americans have for many years been denied opportunities for forms of achievement which are most recognized and valued in society, including political leadership, positions of economic power and high status, positions recognizing accomplishment in academic, intellectual and even many parts of artistic life. As in the first of the three cases I just considered, this denial is itself a form of unfairness: the process through which these positions and the rewards connected with them were awarded was unfair because women and blacks were not given the chance to compete. But this unfairness 
is not the only evil involved, and not the one I want to focus on. It is unfair, and wounding, to be denied important opportunities because of your race or gender. But one thing that makes this particularly wounding is the fact that race and gender are commonly taken to be signs of the lack of substantive qualification: stigmatization is added to unfairness when there is the (perhaps unstated) supposition that because you are not a white male you are less able to contribute to society and its culture in those ways that are regarded as particularly valuable and important.

Suppose now that all the underlying unfairness in ths case were removed, and that everyone had a chance to compete on "equal terms." Assuming that the number of desired positions remained the same, and the number of competitors for them did not decrease, some people (a racially and sexually diverse group, let us suppose) would still be denied these rewards, and while they would not be excluded "from the start" by being ruled out of the competition they will, in an important sense, be denied rewards on the same grounds that women and blacks were: they will be judged to lack the relevant abilities and attainments. I will suppose that this meritocratic discrimination is not unfair: (1) it is not based on unfounded assumptions about differences in ability but on actual, demonstrated differences, and (2) it is not unnecessary but serves important social goals. Nonetheless, as Thomas Nagel has pointed out, ${ }^{11}$ the resulting differences in status and treatment are still to be regretted as objectionable inequalities. The evil involved is the one we have been considering: though not unfair, this meritocracy can be expected to deprive some people of a secure sense of self-worth-of the sense of their own value and the belief that their lives and accomplishments are worthwhile.

This evil, being deprived of important grounds for a sense of selfworth, is, as I have said, one of the important evils underlying the forms of discrimination with which we are familiar. In the case we are imagining these forms of discrimination have been removed, but the relevant experiential evil may remain and may even be aggravated in two respects. First, the inferiority would not be a matter of superstition, but will be documented by fair social practices. Second, if this fair meritocracy has been reached through a process of overcoming discrimination this history is likely to have the effect of dramatizing the value of the rewards and accomplishments in question and belittling the value of a life lived without them. In order to rouse the oppressed to battle and kindle sympathy and guilt in others, one would naturally emphasize not only the unfairness of discrimination but also the importance of 
the opportunities and forms of accomplishment and recognition in question, and the great value of a life with these things as compared to one without them. This has the effect of condemning the lives which victims of discrimination have had to lead, and hence also the lives which others will continue to lead once this discrimination is overcome. Overcoming it may represent a gain in fairness, but there may be no decrease, and perhaps even an increase, in objectionable consequences of inequality of the particular kind I am presently discussing.

I am not urging the fatalist thesis that people should "stay in their places" since inequality cannot be eliminated but only shifted around. I am all in favor of the elimination of discrimination and the reduction of inequality. My aim here is to understand the diversity of the evils which it involves. An egalitarianism which decries the evil I am characterizing may seem hopelessly utopian, because it may seem that the distinctions which give rise to it can never be avoided. Trying to eliminate them may seem to involve unacceptable costs not only in economic efficiency and the quality of the products of a culture but also in individual fulfillment. One thing individuals naturally and reasonably want is to develop their talents and to exercise these realized abilities. Given an uneven distribution of talents, one result of this is that some will inevitably be distinguished from others in ways that generate the problem I have been discussing. Rousseau ${ }^{12}$ can be read as suggesting that this is an inevitable and even tragic conflict. Even if one does not hold out much hope for eliminating this conflict, however, it is possible to conceive of some ways of at least reducing it.

The degree to which the accomplishment and rewards of some people undermine the grounds of other people's sense of self-worth depends upon the degree to which particular forms of ability and accomplishment are regarded as having pre-eminent importance. Even a highly differentiated meritocratic system of offices and rewards might not undermine the self-respect of those who are not successful in it if the attainments which it recognizes and rewards are regarded as less important indices of self-worth than good moral character, conscientiousness as a citizen, and devotion to the well-being of one's family and friends. A society which accorded these qualities their proper value might be able to enjoy the benefits of rewarding accomplishment without suffering the consequences which I am here decrying. ${ }^{13}$

A second strategy is diversification. If there are many different forms of accomplishment and distinction no one, or no few, of which dominate as the socially important measures of success in life, then the threat to people's sense of self-worth will be mitigated. This solution has been 
proposed, in different forms, by both Rawls and Michael Walzer. Walzer has suggested ${ }^{14}$ that if there are many forms of inequality, each confined to its own "sphere," they will to some extent cancel each other out, and their effects will be acceptable-even appropriate and desirable. Rawls, on the other hand, has spoken of the partition of society into what he calls "noncomparing groups":

... the plurality of associations in a well-ordered society, each with its own secure internal life, tends to reduce the visibility, or at least the painful visibility, of variations in men's prospects. For we tend to compare our circumstances with others in the same or in a similar group as ourselves, or in positions that we regard as relevant to our aspirations. The various associations in society tend to divide it into so many noncomparing groups, the discrepancies between these divisions not attracting the kind of attention which unsettles the lives of those less well placed. ${ }^{15}$

Each of these proposals may seem unsatisfactory when understood as a general response to inequality; but there is much to be said for them when they are seen, in a more limited way, as a response merely to the aspect of inequality which I am presently discussing. Walzer, for example, advocates "complex equality" as a general solution to the problem of inequality. He argues that inequalities in wealth, power, fame and other goods are acceptable as long as each good is distributed on the grounds appropriate to it, and no one good is allowed to "dominate" the others as, for example, when wealth is used to buy power, fame, medical care and so on. In addition, he couples this view with a denial that there are general standards of justice which every society must satisfy. Both of these doctrines-his doctrine of "spheres" and his relativistic thesis-have been widely criticized. But the idea of complex equality is more appealing if we view it merely as a way of mitigating the conflict between the protection of self-worth and the necessity of recognizing differences in ability and accomplishment. There is some plausibility to the claim that this problem is best approached not by trying to minimize differences but rather by fostering a healthy multiplicity of distinctions and by trying to insure that no one (or no few) of these "dominates" the others by becoming established as the form of distinction that really matters.

Similarly, Rawls's idea of noncomparing groups has been criticized because it has been seen as a way of making unacceptable inequalities seem acceptable by hiding them. But Rawls is supposing that the inequalities in question already satisfy principles of justice: they are justified in the 
way that the Difference Principle requires, and conditions of fair equality of opportunity are assumed to obtain. The point could be put by saying that people are owed more than fairness in the distribution of concrete goods: they are also owed a concern for the maintenance of their sense of self-worth (in his terms, self-respect) and this is, as I argued above, importantly a matter of the character of their experience. Whether they reasonably feel a loss of self-worth is a function not only of the inequalities which they know exist but of the way in which those inequalities figure in their lives. As far as this concern goes, then, the device of noncomparing groups may be a perfectly appropriate one.

I suggested earlier that the particular egalitarian concern which I have been discussing in this section-the problem of stigmatizing differences in status-is a source of strong motives for opposing inequality and a source which is more purely egalitarian than most of the others I have enumerated. About its motivational strength there seems to me to be no doubt. The instinct to preserve the grounds of one's self-esteem and to oppose what threatens it is a powerful force in the world today, supporting not only struggles for greater equality but also, I would argue, forms of nationalism and nativism, religious fundamentalism and racial and religious bigotry. It is commonly said, for example, that many white males see doctrines of racial and gender equality as a threat to their sense of standing and self-worth.

What has to be claimed is that these reactions, however real they may be, are not reasonable and therefore do not support objections of the kind I have been discussing. In other cases, reasonable feelings of loss of selfesteem may be deserved, hence again not objectionable. ${ }^{16}$ What should be claimed, then, is that a regime of equality would be one that protected its members adequately against reasonable and undeserved feelings of loss of self-esteem.

To conclude: relief of suffering, avoidance of stigmatizing differences in status, prevention of domination of some by others, and the preservation of conditions of procedural fairness are basic and important moral values. Within the framework of the principle of equal consideration they provide strong reasons for the elimination of various inequalities. Taken together these values account for at least a large part of the importance that equality has in our political thinking. They may account for all of this importance, or there may be an important role to be played by a further moral idea of substantive equality. But it remains unclear exactly what that idea would be. 


\section{NOTES}

1. See Nagel, "Equality" in Mortal Questions (Cambridge: Cambridge University Press, 1979), and Sen, Inequality Reexamined (Cambridge, Mass.: Harvard University Press, 1992), p. 13.

2. See, for example, Robert Nozick's objections in Chapters 7 and 8 of Anarchy, State and Utopia (New York: Basic Books, 1974), I was led to the basic ideas of this lecture in the course of working on a review of Nozick's book. Some of these ideas were briefly stated in that review, "Nozick on Rights, Liberty and Property," Philosophy E Pub. lic Affairs 6 (1976).

3. A point made by Derek Parfit in his 1991 Lindley Lecture, "Equality or Priority?". Harry Frankfurt has gone further, suggesting that we replace concern for equality with concern for "sufficiency." He writes, "What is important from the moral point of view is not that everyone should have the same but that each should have enough. If everyone had enough, it would be of no moral consequence whether some had more than others." See Frankfurt, "Equality as a Moral Ideal," in The Importance of What We Care About (Cambridge University Press, 1988), pp. 134-5. In the present lecture I will be investigating whether, contrary to what Frankfurt says in this last sentence, there are further reasons for caring about equality beyond the one I have so far identified.

4. A Theory of Justice (Cambridge, Mass.: Harvard University Press, 1971), p. 154.

5. That this is Rawls's intent is made clear in A Theory of Justice, esp. pp. 83-89. It is natural to think of "equality of opportunity" solely in terms of the competition for economic advantage and positions of special status. In order for the considerations mentioned under (4) above to be fulfilled, however, it is essential to preserve the fairness of competition in the political realm. Rawls clearly believes and considers it important that this condition (what he calls "the fair value of political liberty") will be met when his Two Principles are satisfied (see A Theory of Justice, pp. 224-227), but he does not make this an explicit condition on the inequalities permitted by the Difference Principle.

6. See $A$ Theory of Justice, pp. 72-73.

7. I defend the claim that this is the best way to understand the disagreement between Rawls and Nozick in Lecture 2 of "The Significance of Choice," The Tanner Lectures in Human Values VII, S. McMurrin, ed. (Cambridge: Cambridge University Press, 1988).

8. The more controversial character of appeals to (5) may seem to reflect the fact, mentioned above, that (5) represents a stronger egalitarian idea, since (4) appears at first to be compatible with wide inequality of output. This apparent difference may turn out to be illusory, however, once it is noticed how the benefits assigned to members of one generation affect the starting places of the next. Rawls's version of (4) is not the familiar, weak idea of equal opportunity, and the degree of equality required to secure fairness of starting places seems likely to be very great indeed. But the degree to which this observation makes the egalitarian consequences of (4) more stringent is precisely the area of disagreement over the interpretation of "fair grounds of competition" which was mentioned above.

9. Russ Shafer-Landau pointed out in the discussion following this lecture that Rawls's inclusion of the "social bases of self-respect" in the list of primary social goods (i.e. the measure of distributive shares) represents an integration of my (2) into (5). The result is a focus not on "stigmatization" in general but on equality in the distribution of those social indicators of status that it is the business of basic institutions to define and distribute.

10. See Rawls, $A$ Theory of Justice, p. 440.

11. In "Equal Treatment and Compensatory Discrimination," Philosophy and Public Affairs 2 (1973), reprinted as "The Policy of Preference" in Mortal Questions. My thought 
experiment also has obvious similarities to Michael Young's famous fable, The Rise of the Meritocracy, 1870-2033 (Harmondsworth: Penguin Books, 1963).

12. In his First and Second Discourses. But it seems likely that his concern was more with what might be called a loss of fraternity than with what I have here termed a blow to individual self-respect.

13. It might be countered (as Richard De George pointed out in the discussion following this lecture) that since people are bound to be unequal in these "moral attainments" a society which gave them pre-eminent place would be just another form of meritocracy, admirable in some respects, perhaps, but just as damaging (maybe even more damaging) to the self-respect of those whom it condemns. The reply, I suppose, is that these feelings of loss of self-respect, if deserved, would not be objectionable.

14. In his book, Spheres of Justice (New York: Basic Books, 1983).

15. A Theory of Justice, pp. 536-7.

16. See footnote 13 above. 
The following lectures have been published in individual pamphlet form and may be obtained from the Department at a price of $\$ 2.50$ plus $\$ 1.00$ for handling ( $\$ 3.50$ per lecture).

*1961. "The Idea of Man-An Outline of Philosophical Anthropology." By José Ferrater Mora, Professor of Philosophy, Bryn Mawr College.

1962. "Changes in Events and Changes in Things."

By A. N. Prior, Professor of Philosophy, University of Manchester.

*+1963. "Moral Philosophy and the Analysis of Language."

By Richard B. Brandt, Professor of Philosophy, Swarthmore College.

*†1964. "Human Freedom and the Self."

By Roderick M. Chisholm, Professor of Philosophy, Brown University.

†1965. "Freedom of Mind."

By Stuart Hampshire, Professor of Philosophy, Princeton University.

*†1966. "Some Beliefs about Justice."

By William K. Frankena, Professor of Philosophy, University of Michigan.

†1967. "Form and Content in Ethical Theory."

By Wilfrid Sellars, Professor of Philosophy, University of Pittsburgh.

$\dagger 1968$. "The Systematic Unity of Value."

By J. N. Findlay, Clark Professor of Philosophy, Yale University.

1969. "Buber and Buberism-A Critical Evaluation."

By Paul Edwards, Professor of Philosophy, Brooklyn College of the City University of New York.

1971. "What Actually Happened."

By P. H. Nowell-Smith, Professor of Philosophy, York University.

†1972. "Moral Rationality."

By Alan Gewirth, Professor of Philosophy, University of Chicago.

$\uparrow 1973$. "Reflections on Evil."

By Albert Hofstadter, Professor of Philosophy, University of California, Santa Cruz

$\dagger+1974$. "What is Dialectical?"

By Paul Ricoeur, Professor of Philosophy, University of Paris and University of Chicago.

† 1975. "Some Confusions About Subjectivity."

By R. M. Hare, White's Professor of Moral Philosophy at Oxford

University and Fellow of Corpus Christi College.

1976. "Self-Defense and Rights."

By Judith Jarvis Thomson, Professor of Philosophy, Massachusetts Institute of Technology.

1977. "What is Humanism?"

By Georg Henrik von Wright, Research Professor of Philosophy, The Academy of Finland.

1978. "Moral Relativism."

By Philippa Foot, Senior Research Fellow, Somerville College, Oxford; and Professor of Philosophy, University of California, Los Angeles.

1979. "The Idea of the Obscene."

By Joel Feinberg, Professor of Philosophy, University of Arizona.

1980. "Goods Beyond Price and Other Apparent Anachronisms."

By Warner Wick, Professor of Philosophy, University of Chicago.

1981. "Morality, Property and Slavery."

By Alan Donagan, Professor of Philosophy, University of Chicago. (continued, back cover)

* Pamphlet out of print.

† Reprinted in Freedom and Morality.

† Printed only in Freedom and Morality. 
1982. "Expressing Evaluations."

By Donald Davidson, Professor of Philosophy, University of California, Berkeley.

1983. "How Not to Solve Ethical Problems."

By Hilary Putnam, Professor of Philosophy, Harvard University.

1984. "Is Patriotism a Virtue?"

By Alasdair MacIntyre, W. Alton Jones Professor of Philosophy, Vanderbilt University.

1985. "How Free Does the Will Need to Be?"

By Bernard Williams, Provost of King's College Cambridge.

1986. "Moral Agent and Impartial Spectator."

By Gilbert Harman, Professor of Philosophy, Princeton University.

1987. "Projection and Truth in Ethics."

By John McDowell, Professor of Philosophy, University of Pittsburgh.

1988. "The Politics of Imagination."

By Arthur Danto, Professor of Philosophy, Columbia University.

1989. "Constituting Democracy."

By David Gauthier, Distinguished Service Professor of Philosophy, University of Pittsburgh.

1990. "Justice and the Good Life."

By Ronald Dworkin, Professor of Jurisprudence, Oxford University, New.York University Law School.

1991. "Equality or Priority?"

By Derek Parfit, Professor of Philosophy, All Souls College, Oxford, Harvard University.

1992. "Objectivity and Position."

By Amartya Sen, Lamont University Professor and Professor of

Economics and Philosophy, Harvard University.

1994. "Families, Nations, and Strangers."

By Samuel Scheffler, Professor of Philosophy, University of California, Berkeley.

1995. "Wittgenstein on Practice and the Myth of the Giving."

By Susan Hurley, Professor of Political and Ethical Theory, University of Warwick. 